\title{
A Comparative Study of Bupivacaine $0.5 \%$ and Ropivacaine $0.75 \%$ for Supra-Clavicular Brachial Plexus Block Using Nerve Locator for Elective Upper Limb Orthopaedic Surgeries
}

\author{
Amol Singam ${ }^{1}$, Punith M. Sirige ${ }^{2}$ \\ 1,2 Department of Anaesthesiology, Jawaharlal Nehru Medical College, \\ DMIMS, Sawangi, Wardha, Maharashtra, India.
}

\section{ABSTRACT}

\section{BACKGROUND}

Regional anaesthesia has multiple advantages as compared to general anaesthesia for upper limb surgeries. Here in this study, we wanted to compare bupivacaine $0.5 \%$, commonly used anaesthetic with ropivacaine $0.75 \%$ which has fewer side effects like cardiotoxicity for supraclavicular brachial plexus block.

\section{METHODS}

A study was performed on 60 ASA I \& II patients aged between 18 and 75 years, undergoing upper limb elective surgeries under brachial plexus block using nerve locator. Beginning of sensory and motor block, general nature of block, and terms of sensory and motor blocks were assessed in the C5 to T1 dermatomes.

\section{RESULTS}

There was no statistically significant difference in the onset of sensory and motor blockade between ropivacaine $0.75 \%$ and bupivacaine $0.5 \%$. Ropivacaine $0.75 \%$ produced similar quality of motor and sensory blockade compared to $0.5 \%$ bupivacaine. The time taken for maximum motor blockade with ropivacaine was comparable with that of bupivacaine $0.5 \%$. There was no statistically significant difference regarding the duration of analgesia with ropivacaine $0.75 \%$ compared to bupivacaine $0.5 \%$. Duration of motor blockade with $0.75 \%$ ropivacaine was comparable to that of $0.5 \%$ bupivacaine.

\section{CONCLUSIONS}

Ropivacaine $0.75 \% 0.4 \mathrm{ml} / \mathrm{kg}$ or $0.5 \%$ bupivacaine $0.4 \mathrm{ml} / \mathrm{kg}$ for supraclavicular brachial plexus block produces satisfactory and comparable sensory and motor blockade. It is suggested that lower cardiovascular toxicity of ropivacaine with equal efficacy as bupivacaine in such circumstances may help in reducing the risks to the patient.

\section{KEY WORDS}

Bupivacaine $0.5 \%$, Ropivacaine $0.75 \%$, Brachial Plexus Block, Upper Limb Orthopaedic Surgeries
Corresponding Author: Dr. Punith M. Sirige, Department of Anaesthesiology Jawaharlal Nehru Medical College, DMIMS, Sawangi, Wardha, Maharashtra, India.

E-mail: Punithsirige25@gmail.com

DOI: $10.14260 / \mathrm{jemds} / 2021 / 377$

How to Cite This Article:

Singam A, Sirige PM. A comparative study of bupivacaine $0.5 \%$ and ropivacaine $0.75 \%$ for supra-clavicular brachial plexus block using nerve locator for elective upper limb orthopaedic surgeries.J Evolution Med Dent Sci 2021;10(24):1825-1829, DOI: $10.14260 /$ jemds/2021/377

Submission 01-02-2021,

Peer Review 17-04-2021,

Acceptance 23-04-2021,

Published 14-06-2021.

Copyright (c) 2021 JEMDS. This is an open access article distributed under Creative Commons Attribution License [Attribution 4.0 International (CC BY 4.0)] 


\section{BACKGROUND}

Anaesthesia has evolved into a specialty subject over decades with lot of improvements in the methods employed and drugs used to provide anaesthesia with least complications. General anaesthesia was one of the most common methods employed to provide anaesthesia for upper limb surgeries. With the introduction of newer and safer local anaesthetics and better advantages, regional anaesthesia has taken over as the principle technique for upper limb surgeries.

There are many advantages ${ }^{1}$ of brachial plexus block for upper limb surgeries over general anaesthesia, namely

1. effective analgesia with good motor blockade

2. awake patient

3. extended post-operative analgesia

4. early ambulation

5. early resumption of oral feeding

6. minimal number of drugs used so that polypharmacy is avoided.

7. no airway manipulation

8. less incidence of post-operative nausea and vomiting

9. ideal operating conditions can be met

10. post anaesthesia cure unit (PACU) and ward nurses particularly appreciate the use of regional anaesthesia

Various approaches ${ }^{1,2}$ of brachial plexus block has been used for upper limb surgeries namely

1. Interscalene approach

2. Supraclavicular approach

3. Infraclavicular approach

4. Axillary approach

Among these approaches supraclavicular and infraclavicular techniques are more effective in producing complete anaesthesia of all the branches of the brachial plexus as the narrowest part of the plexus is encountered by these techniques. Supraclavicular approach is easier than the infraclavicular approach as the plexus is more superficial above the clavicle. Various local anaesthetics have been used to produce brachial plexus block. Bupivacaine $0.5 \%$ is one of the most popular drugs used because of its higher potency and prolonged duration of action. One of the drawbacks of Bupivacaine is its cardiotoxicity especially when injected accidentally into the subclavian artery. ${ }^{3}$ The cardiotoxicity may be life threatening as the dysrhythmias produced are resistant to all routinely used antiarrhythmics. Hence there is a need for a drug which has all the advantages of Bupivacaine without its cadiotoxicity. 4

Ropivacaine is a new amino amide local anaesthetic which has similar structure as Bupivacaine, has all its advantages but without any cardiotoxicity. ropivacaine was introduced as regional anaesthesia in western countries in the 1990s. It has been recently introduced in India.

Not many studies have been done using ropivacaine for brachial plexus block in India. Therefore, there is a need to study the effectiveness of ropivacaine as a local anaesthetic for supraclavicular brachial plexus block. Hence a study was undertaken to compare the routinely used bupivacaine with recently introduced ropivacaine for brachial plexus block for elective upper limb surgeries. ${ }^{5-6}$

\section{METHODS}

A prospective comparative study was conducted for a period of 1 year from November 2019 to November 2020 in the Department of Anaesthesia of JNMC and AVBRH, Wardha, Maharashtra, after ethical committee clearance was obtained on 19/12/2019. ref No-DMIMS(DU)/IEC/Dec-2019/1576 along with the written consent.

\section{Inclusion Criteria}

1. Patients belonging to ASA 1 and 2,

2. Patients of either gender between 18 and 75 years, of age group,

3. Patients undergoing elective upper limb orthopaedic surgeries.

\section{Exclusion Criteria}

1. Patients with critical cardiovascular sickness,

2. Hypertension, diabetes,

3. Renal failure, hepatic dysfunction,

4. Ongoing respiratory illness, neuro muscular disorders,

5. Bleeding disorders, skin disorders at local site,

6. Uncooperative patients.

All patients posted for elective upper limb surgeries were assessed preoperatively and baseline heart rate and blood pressure noted. After clinical evaluation, patients were shifted to OT and multipara monitors like ECG, SPo2, non-invasive blood pressure (NIBP) were connected to the patients. 18 G IV cannula was secured, and infusion of Ringer's lactate had begun at the pace of $80 \mathrm{ml} / \mathrm{hr}$., All baseline parameters were noted. Emergency medications and equipment's for GA were kept prepared. Study drug was set up in a sterile bowl by taking $0.4 \mathrm{ml} / \mathrm{kg}$ of $0.75 \%$ ropivacaine and $0.4 \mathrm{ml} / \mathrm{kg}$ of 0.5 $\%$ bupivacaine. Patients were randomly divided into two groups by a computer-generated simple randomization.

- $\quad$ Group $\mathrm{R}(\mathrm{N}=30)$ received $0.4 \mathrm{ml} / \mathrm{kg}$ of $0.75 \%$ ropivacaine

- Group B $(\mathrm{N}=30)$ received $0.4 \mathrm{ml} / \mathrm{kg}$ of $0.5 \%$ bupivacaine

Block was given by subclavian perivascular strategy using nerve locator, Stimuplex Burrow, (B. Braun, Allentown, Dad) a 22 - measure, 2 - inch, short-slant protected needle. Patients were made supine position with head tilt to other side. Under all aseptic precautions, the skin was punctured 1 finger above the lowermost part of the inter scalene groove lateral to subclavian artery pulsations. The force of current was at first set to convey $0.9 \mathrm{~mA}$ with incitement recurrence set at $1 \mathrm{~Hz}$, the needle was progressed straightforwardly caudally until we saw the contraction in the flexor or extensor compartment, and current was slowly diminished to $0.4 \mathrm{~mA}$.

In the event that the contraction was yet to be noticed, the local anaesthetic study drug was administered. If by mistake any arterial puncture was noticed, the block needle was removed somewhat and its heading was changed. Vital parameters, for example, HR, respiratory rate, Sp02 and pulse 
were observed for every $5 \mathrm{~min}$ for initial $30 \mathrm{~min}$ and from then on every $15 \mathrm{~min}$ till the end of procedure.

Two minutes after block, Sensory block was assessed at 1 min stretch by pinprick method testing more than 4 significant nerve conveyance regions (Radial, Ulnar, Median and Musculocutaneous) on a three - point scale (0 - typical sensation; 1 - gruff sensation; 2 - no sensation) motor block was assessed with modified Bromage scale (MBS; 0 - Ordinary muscle function, 1 - Elbow flexion, 2 - Wrist flexion, 3 - Full motor block).

- Onset of Sensory block: Time from end of injection of study drug to pinprick test score of 1.

- $\quad$ Onset of Motor Block: Time from end of injection of study drug to appearance of MBS grade I.

- $\quad$ Complete Sensory Block: Time from end of injection of study medication to pinprick test score of 2.

- Complete Motor Block: Time from end of injection of study medication to appearance of MBS grade 3 .

- Duration of Surgery: The span between first skin incision and end of surgery

- Length of Motor Block: Time between motor block beginning and full arm mobility (MBS grade 0 ).

The duration of analgesia was noted by the 0 - 10 visual analogue scale (VAS). ${ }^{10}$ where 0 means no pain and 10 means very bad pain. VAS evaluation was done postoperatively half hourly for $12 \mathrm{~h}$ and then every hourly till the patient complained of pain. Rescue pain Inj. diclofenac $75 \mathrm{mg}$ IM was injected when VAS was 4 or more.

If there was pain sensation during surgery, local anaesthetic infiltration by inj. lignocaine $1.5 \%, 5-10 \mathrm{ml}$ was done. If pain persisted $50 \mathrm{ug}$ fentanyl alongside $1 \mathrm{mg}$ midazolam was given IV. The dosages were recorded whenever managed. All patient's complaints during and after the block, its complications and results of medication were recorded.

\section{Statistical Analysis}

According to previous study by Kaur A et al. Mean and SD deviation of duration of block were $408.40 \pm 50.39 \mathrm{~min}$ in bupivacaine group and $365.60 \pm 34.29 \mathrm{~min}$ in ropivacaine group

With alpha of $5 \%$ and $80 \%$ power, the sample size calculated was 21, which was rounded off to 30 study participants per group.

$\mathrm{n}=(\mathrm{Z} \propto / 2+\mathrm{Z} \beta) 2^{*}[\mathrm{p} 1(100-\mathrm{p} 1)+\mathrm{p} 2(100-\mathrm{p} 2)] /(\mathrm{p} 1-\mathrm{p} 2) 2$

where,

$\mathrm{Z} \alpha / 2$ is the critical value of the Normal distribution at $\alpha$ of 0.05 , i.e. 1.96 ,

$\mathrm{Z} \beta$ is the critical value of the Normal distribution at $\beta$ of $20 \%$ (power of $80 \%$ ), i.e. 0.84 and p1 and p2 are $40 \%$ and $15.5 \%$ respectively.

$\mathrm{N}=21$

which was rounded off to 30 study participants per group.

Statistical Package for Social Sciences version 15.0, chisquare test was used to evaluate the proportional data. Odds ratio / risk ratios have been calculated wherever necessary.
Parametric data has been evaluated using Student t-test while non-parametric data has been evaluated using Mann-Whitney U-test.

\section{RESULTS}

\begin{tabular}{|cccc|}
\hline Patient Characteristics & Group R & Group B & P Value \\
Age (years) & $38.67 \pm 13.37$ & $39.7 \pm 15.49$ & 0.7831 \\
Weight (kg) & $60.93 \pm 6.65$ & $57.7 \pm 7.6$ & 0.09 \\
Gender (M / F) & $19 / 11$ & $16 / 14$ & 0.601 \\
Duration of surgery & $79.57 \pm 19.33$ & $86.28 \pm 15.28$ & 0.089 \\
\hline \multicolumn{4}{c|}{ Table 1. Demographic Data } \\
\hline
\end{tabular}

\begin{tabular}{|cccc|}
\hline Block Characteristics & Group R & Group B & P Value \\
Onset of motor block (min) & $4.63 \pm 3.64$ & $4.4 \pm 2.02$ & 0.76 \\
Onset of sensory block (min) & $3.65 \pm 2.914$ & $914.23 \pm 1.59$ & 0.13 \\
Complete motor grade & 2 in $93.33 \%$ & 2 in $90 \%$ patients & 0.64 \\
Duration of motor block (min) & $596 \pm 154.14$ & $598.52 \pm 141.13$ & 0.95 \\
Total duration of analgesia (min) & $555.14 \pm 162.26$ & $594.33 \pm 158.73$ & 0.36 \\
\hline \multicolumn{2}{|c|}{ Table 2. Block Characteristics and Duration of Analgesia } \\
\hline
\end{tabular}

A sum of 60 patients were concentrated in the age group of 18 - 75 years of either sex. Number of surgeries conducted in the age group of 20 - 30 years was $53.3 \%$. Total number of males who underwent surgeries were more as compared to females that was $80 \%$ males and $20 \%$ females. There was no significant difference in both the groups in terms of age, weight, gender $(\mathrm{P}>0.05)$.

Onset of motor block was $4.63 \mathrm{~min}$ in R group and $4.4 \mathrm{~min}$ in B group. The total motor block was accomplished in 12.41 min in R group and 10.70 min in B group. There was no significant difference between the two groups for paresis or paralysis of one or the other shoulder or hand. The block was adequate in $93.33 \%$ patients in R group and $90 \%$ patients in B group. There was no significant difference in sensory block onset, motor block onset, duration of motor block, duration of sensory block in both the groups. Frequency of haematoma, pneumothorax, accidental intravascular injection, back flow of drug, spasms, neuralgia were nil in one or the other group. There was no significant difference in haemodynamic variables in both the groups.

There was no significant difference in duration of sensory and motor blockade between the ropivacaine and bupivacaine groups $(\mathrm{P}>0.05)$. The duration of sensory blockade was from 206 to $1033 \mathrm{~min}$ for ropivacaine and 250 to $990 \mathrm{~min}$ for bupivacaine, while the duration of motor block was from 260 to $1144 \mathrm{~min}$ for ropivacaine and 330 to $990 \mathrm{~min}$ for bupivacaine.

\section{DISCUSSION}

A prospective comparative study of ropivacaine $0.75 \%$ and bupivacaine $0.5 \%$ for supraclavicular brachial plexus block employing subclavian perivascular approach using nerve stimulator for elective upper limb orthopaedic surgeries. Under all aseptic precautions supraclavicular subclavian perivascular brachial plexus block was done as depicted by Winnie using either $0.4 \mathrm{ml} / \mathrm{kg} 0.75 \%$. ropivacaine or $0.5 \%$ bupivacaine and different boundaries were studied. ${ }^{7}$ In our study, the medications chosen for brachial plexus block were bupivacaine and ropivacaine. Bupivacaine as a rule is routinely used for brachial plexus block for upper limb surgeries in our hospital. Ropivacaine, another local anaesthetic with 
similarities to bupivacaine without its cardiotoxic effect has been acquainted in Indian market. Ropivacaine has been discovered to be similarly compelling as bupivacaine for brachial plexus block by different authors. ${ }^{8}$ Not many studies were done on bupivacaine and ropivacaine for brachial plexus block in India. Thus, ropivacaine was chosen as local anaesthetic drug for our study in contrast to regularly used bupivacaine. ${ }^{9-10}$

\section{Sensory Block Onset}

The onset of sensory block in our study was evaluated at different dermatomal levels. The beginning of sensory block was before in C6 dermatome - $3.65 \mathrm{~min}$ and deferred at T1 dermatome $-6.66 \mathrm{~min}$ in $\mathrm{R}$ group. The onset of sensory block was before in $\mathrm{C} 5$ dermatome $-3.65 \mathrm{~min}$ and deferred at T1 Dermatome $7.47 \mathrm{~min}$ in B group. There was no significant difference between $0.75 \%$ ropivacaine and $0.5 \%$ bupivacaine with respect to the onset of sensory block.

\section{Motor Block Onset}

The onset of motor block in our study was evaluated at shoulder and hand. The beginning of motor block in ropivacaine group was 4.63 minutes and bupivacaine group was 4.4 minutes. The total motor block was accomplished in 12.41 minutes in ropivacaine group and 10.7 minutes in bupivacaine group. There was no significant difference $(\mathrm{P}>$ 0.05 ) between the two groups with respect to the onset of motor blockade and in the time taken for completion of motor blockade.

\section{Duration of Analgesia}

The duration of analgesia was 555.14 minutes in ropivacaine group and 594.33 minutes in bupivacaine group. There was no significant difference in both the groups.

\section{Quality of Motor Blockade}

$93.33 \%$ of the patients in ropivacaine group and $90 \%$ in bupivacaine group had total paralysis of both the shoulders and hands. There was no significant difference in both the groups.

\section{Duration of Motor Blockade}

The duration of motor blockade was $596.04 \mathrm{~min}$ in bupivacaine group and 598.52 minutes in ropivacaine group and there was no significant difference in both the groups.

\section{Overall Quality of Block}

The block was adequate in most of the patients in either group representing $93.33 \%$ in $\mathrm{R}$ group and $90 \%$ in B group. The excess patients had inadequate block, and they were given sedation and rejected from the study.

\section{Adverse Events}

The occurrence of hematoma, pneumothorax, inadvertent intravascular injection, Post block queasiness / vomiting / spasms / neuralgia were nil in both the groups. Our study shows that convergence of $0.75 \%$ ropivacaine is similarly powerful as $0.5 \%$ bupivacaine when compared with onset and duration and nature of sensory and motor blockade.

\section{CONCLUSIONS}

There was no statistically significant difference in the onset of sensory and motor blockade between ropivacaine $0.75 \%$ and bupivacaine $0.5 \%$. Ropivacaine $0.75 \%$ produces similar quality of motor and sensory blockade compared to $0.5 \%$ bupivacaine. The time taken for maximum motor blockade with ropivacaine is comparable with that of bupivacaine $0.5 \%$. There is no statistically significant difference in the duration of analgesia with ropivacaine $0.75 \%$ when compared to that of bupivacaine $0.5 \%$. Duration of motor blockade with $0.75 \%$ ropivacaine is comparable to that of $0.5 \%$ bupivacaine.

Hence it can be concluded that ropivacaine $0.75 \% 0.4 \mathrm{ml} /$ $\mathrm{kg}$ or $0.5 \%$ bupivacaine $0.4 \mathrm{ml} / \mathrm{kg}$ for supraclavicular brachial plexus block produce satisfactory and comparable sensory and motor blockade. Accidental intravascular injection of local anaesthetic is a problem in spite of meticulous technique and is particularly worrisome when large volume of anaesthetic is required for efficacy. It is suggested that the lower cardiovascular toxicity of ropivacaine with equal efficacy as bupivacaine, in such circumstances may help in reducing the risks to the patient.11,12

Data sharing statement provided by the authors is available with the full text of this article at jemds.com.

Financial or other competing interests: None.

Disclosure forms provided by the authors are available with the full text of this article at jemds.com.

\section{REFERENCES}

[1] Cousins MJ, Bridenbaugh PO, Carr DB, et al. Neural blockade in clinical anaesthesia and pain medicine. $4^{\text {th }}$ edn. Lippincott Williams and Wilkins 2009.

[2] Morgan EG, Mikhail MS, Murray MJ. Peripheral nerve blocks. Chap. 17. $4^{\text {th }}$ edn. In: Clinical anaesthesiology. New Delhi: Tata McGraw-Hill 2009.

[3] McClure JH. Ropivacaine. Br J Anaesth 1996;76(2):300-7.

[4] Pham-Dang C, Gunst JP, Gouin F, et al. A novel of supraclavicular approach to brachial plexus block. Anesth Analg 1997;85(1):111-6.

[5] Berry M, Lawrence H, Susan BM. Standing nervous system. Chap. 8. 38 $8^{\text {th }}$ edn. In: Gray's Anatomy. 1995:9021397.

[6] Collins VJ. Blocks of cervical nerves. Chap. 48. $3^{\text {rd }}$ edn. In: Principles of anaesthesiology. Philadelphia: Lea and Febrigen 1993:1363-84.

[7] Brown DL. Upper extremity block anatomy. Chap. 2. 2nd edn. In: Atlas of regional anaesthesia. WB Saunders Company 1999:13-22.

[8] Winnie AP, Franco CD. Supraclavicular approaches to brachial plexus anaesthesia. anaesthesiology. Vol. 25. WB Saunders Company 1997:353-63.

[9] Hadzik A, Vloka JD. Peripheral nerve blocks-principles and practice. Chap. 4. In: Collin VJ, ed. Local anaesthetics. 
$3^{\text {rd }}$ edn. Principles of anaesthesiology. Philadelphia: Lea and Febiger 1993: p. 1260.

[10] Stoelting RK, Hillier SC. Local anaesthetics. Chap. 7. $4^{\text {th }}$ edn. In: Pharmacology and physiology in anaesthetic practice. Philadelphia: Lippincott Williams and Wilkins 2006:179-99.
[11] Casati A, Putzu M. Bupivacaine, levobupivacaine and ropivacaine: are they clinically different? Best Pract Res Clin Anaesthesiol 2005;19(2):247-68.

[12] Kuthiala G, Chaudhary G. Ropivacaine: a review of its pharmacology and clinical use. Indian J Anaesth 2011;55(2):104-10. 